\title{
Use of fluorescence to visualize response to iloprost treatment for frostbite
}

\author{
Mira MacLennan MD, Alexander Poole MD, Josianne Gauthier MScPharm
}

Cite as: CMAJ 2021 August 9;193:E1219. doi: 10.1503/cmaj.202258

A 48-year old man presented to the emergency department in Whitehorse, Yukon, after 8 hours of exposure to $-47^{\circ} \mathrm{C}$. He was a nonsmoker and otherwise healthy. He had grade 2 frostbite to the left first toe, with cyanosis to the distal interphalangeal joint (Appendix 1, available at www.cmaj.ca/lookup/doi/10.1503/ cmaj.202258/tab-related-content). We used intravenous indocyanine green fluorescence, a water-soluble dye, for baseline visual microvascular assessment and to assess treatment response. We started iloprost $0.2 \mu \mathrm{g} / \mathrm{mL}$ at $10 \mathrm{~mL} / \mathrm{h}$ and increased it to $50 \mathrm{~mL} / \mathrm{h}$ for 6 hours daily for 5 days. We captured fluorescence images before iloprost treatment (Figure $1 \mathrm{~A}$ ) and immediately after the first 6-hour infusion (Figure 1B); microvascular perfusion to the affected toe improved. He tolerated treatment well and did not require amputation.

Information on the epidemiology of frostbite injuries is sparse. One nationwide study in Finland reported an incidence of frostbite of 2.5 cases per 100000 population. ${ }^{1}$ Male sex, advancing age and temperatures of $-20^{\circ} \mathrm{C}$ were associated with an increased risk of frostbite. ${ }^{1}$ Frostbite injuries range in severity from grade 1 (mild) to 4 (severe, high risk of amputation), and can cause substantial morbidity, including pain, joint stiffness and neuropathic pain. ${ }^{2}$ Although consensus on the standard of care for frostbite management is lacking, many European centres use iloprost for grades 2-4 frostbite, and some also use alteplase for grade 4 injuries.,4 Our institution developed a frostbite management protocol, which includes iloprost infusions daily for 5 days for grades $2-4$ frostbite. ${ }^{5}$ Ambulatory patients who tolerate the first infusion may have subsequent infusions as an outpatient.

Intravenous indocyanine green may provide an important means of characterizing patient response to frostbite treatment and optimizing care. ${ }^{6}$ Perfusion is assessed visually by the presence or absence of indocyanine green, using a near-infrared light coupled with a monitor. Comparison of the dye's intensity to surrounding tissues allows a subjective assessment of relative perfusion. Adverse effects are primarily related to allergic reactions, and the only contraindication appears to be iodine allergy. ${ }^{7}$
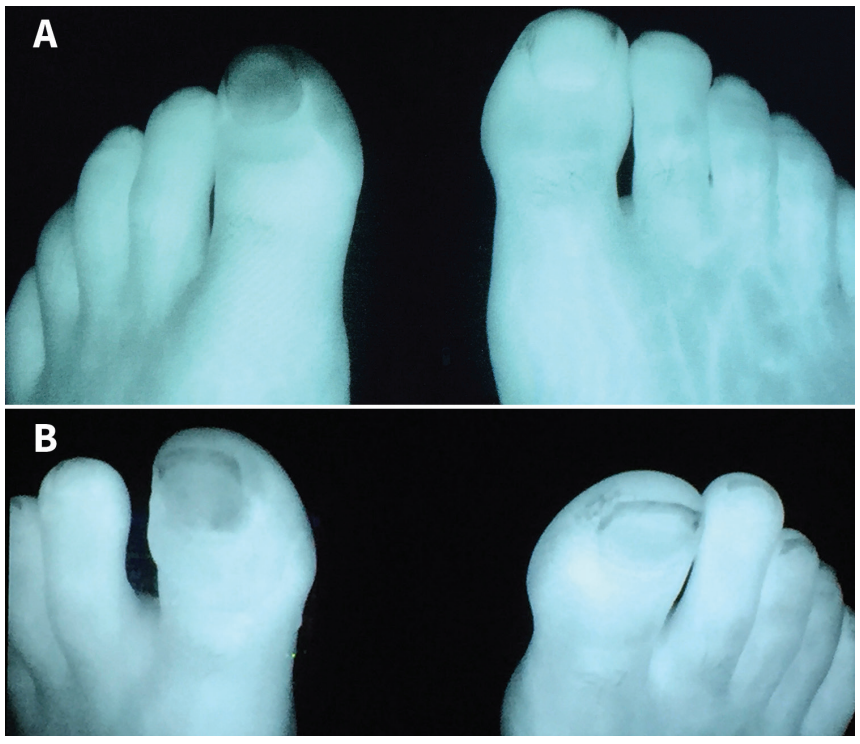

Figure 1: Microvascular assessment of frostbite in the left foot of a 48-year-old man using intravenous indocyanine green. (A) 12 hours after frostbite, before iloprost treatment, with flow defect visible in the distal left first phalanx, compared with uninjured right first phalanx. (B) 6 hours after completion of the first iloprost infusion, with interval improvement of blood flow to the left first phalanx.

\section{References}

1. Juopperi K, Hassi J, Ervasti O, et al. Incidence of frostbite and ambient temperature in Finland, 1986-1995. A national study based on hospital admission. Int J Circumpolar Health 2002;61:352-62.

2. Handford C, Buxton P, Russell K, et al. Frostbite: a practical approach to hospital management. Extrem Physiol Med 2014;3:7.

3. Cauchy E, Cheguillaume B, Chetaille E. A controlled trial of prostacyclin and rt-PA in the treatment of severe frostbite. N Engl J Med 2011;364:189-90.

4. Cauchy $E$, Davis CB, Pasquier M, et al. A new proposal for management of severe frostbite in the austere environment. Wilderness Environ Med 2016;27:92-9.

5. Poole A, Gauthier J. Treatment of severe frostbite with iloprost in northern Canada. CMAJ 2016;188:1255-8.

6. Masters T, Omodt S, Gayken J, et al. Microangiography to monitor treatment outcomes following severe frostbite injury to the hands. J Burn Care Res 2018;39:162-7.

7. Alander JT, Kaartinen I, Laakso A, et al. A review of indocyanine green fluorescent imaging in surgery. Int J Biomed Imaging 2012;2012: 940585.

\section{Competing interests: None declared.}

This article has been peer reviewed.

The authors have obtained patient consent.

Affiliations: Department of Surgery (MacLennan), McMaster University, Hamilton, Ont.; Harvard T.H. Chan School of Public Health (MacLennan), Boston, Mass.; Whitehorse General Hospital (Poole,
Gauthier), Whitehorse, YT; Department of Surgery (Poole), Cumming School of Medicine, University of Calgary, Calgary, Alta.; University of Saskatchewan (Gauthier), Saskatoon, Sask.

Content licence: This is an Open Access article distributed in accordance with the terms of the Creative Commons Attribution (CC BY-NC-ND 4.0) licence, which permits use, distribution and reproduction in any medium, provided that the original publication is properly cited, the use is noncommercial (i.e., research or educational use), and no modifications or adaptations are made. See: https://creativecommons.org/ licenses/by-nc-nd/4.0/

Correspondence to: Mira MacLennan, mira.maclennan@medportal.ca 